\title{
Pescadores de caranguejo de São Caetano de Odivelas/PA: o saber e o fazer na perspectiva da etnomatemática
}

Crab fishermen from São Caetano de Odivelas / PA: the knowledge and the do from the perspective of ethnomathematics

Ronny Gleyson Maciel de Moraes ${ }^{1}$

Erasmo Borges de Souza Filho ${ }^{2}$

\section{Resumo}

Este artigo tem como objetivo descrever os saberes e fazeres presentes nas atividades laborais de pescadores de caranguejo do município de São Caetano de Odivelas, Estado do Pará, e sua importância na Educação Escolar. A fundamentação teórica está situada na perspectiva da Etnomatemática, com base em D’Ambrósio (2002), Barton (2004) e Vergani (2007). A pesquisa apresenta um conteúdo analítico-descritivo constituído obtido por meio de entrevistas, diálogos informais, registros fotográficos e audiovisuais, que constituem a fonte de informações para as análises. No desenvolvimento da pesquisa, destacamos os saberes tradicionais envolvidos na pesca de caranguejo e os reflexos do envolvimento entre o homem e natureza. Tal envolvimento é um elo entre o saber e o fazer compactuados no processo de difusão de conhecimentos dentro desse contexto sociocultural.

Palavras-chave: Educação Matemática. Etnomatemática. Pescadores de caranguejo. Saberes tradicionais.

\section{Introdução}

O ensino-aprendizagem da matemática está em permanente discussão entre pesquisadores, professores e estudiosos, cujos múltiplos olhares buscam compreender as problemáticas envolvidas nas dificuldades apresentadas pelos

\footnotetext{
${ }^{1}$ Mestre em Educação em Ciências e Matemáticas pela Universidade Federal do Pará (UFPA); email: moraesronny@yahoo.com.br

${ }^{2}$ Doutor em Comunicação e Semiótica pela PUC-SP; Docente do Programa de Pós-Graduação em Educação em Ciências e Matemáticas da UFPA; email: erasmo@ufpa.br
} 
alunos no aprendizado da matemática com implicações na busca de alternativas pedagógicas para a melhoria nas práticas educativas dos professores.

Dentre as alternativas, encontra-se a importância de relacionar o conhecimento matemático escolar com as práticas do cotidiano. Essa relação tem sido o foco de interesse nas investigações que acenam para a valorização dos contextos sociais, políticos, culturais e econômicos em práticas pedagógicas no âmbito da Educação Matemática. É nessa perspectiva que a ação pedagógica e a investigação acadêmica, fundamentada na Etnomatemática, têm contribuído efetivamente para uma postura pedagógica diferenciada com a valorização das raízes socioculturais dos educandos, pois "a abordagem a distintas formas de conhecer é a essência do Programa Etnomatemática" (D’AMBRÓSIO, 2002, p. $70)$.

Hoje, as discussões em relação à etnomatemática são constantes. Tal discussão pertence à linha de pesquisa da área de conhecimento da Educação Matemática. Nessa concepção é possível destacar que:

A etnomatemática é uma tentativa de descrever e entender as formas pelas quais, chamados pelos etnomatemáticos de matemática, são compreendidas, articuladas e utilizadas por outras pessoas que não compartilham da mesma concepção de matemática (BARTON, 2004, p. 50).

Evidenciando o que Barton menciona, valorizar a realidade do aluno como estratégia educacional fortalece a visão que a matemática está presente em todos os saberes e fazeres culturais, porém de forma muitas vezes diferenciadas de como a matemática é ensina nas escolas. Nessa perspectiva, a Etnomatemática nos faz refletir em como a aprendizagem pode se tornar mais significativa quando se leva em conta os saberes e práticas culturais de forma contextualizadas resultando em uma abordagem mais próxima a realidade cultural do aluno, explorando situações vivenciadas ou conhecidas no meio social e cultural.

Nesse sentido, considerando os aspectos que envolvem a Etnomatemática, desenvolvemos este artigo acerca dos saberes e fazeres oriundos das práticas tradicionais dos pescadores de caranguejo de São Caetano de Odivelas/PA, fazendo um estudo acerca de todo processo que envolve a pesca de caranguejo, 
fazendo uma interseção entre Etnomatemática e os saberes dessa tradição. $O$ mesmo trata-se de um recorte da dissertação do primeiro autor, intitulada "Saberes e fazeres de pescadores de caranguejo de São Caetano de Odivelas/PA: uma abordagem etnomatemática", desenvolvida na Universidade Federal do Pará (UFPA)

Para alcançar o objetivo proposto, realizamos entrevistas com três pescadores de caranguejo, os quais relataram sobre suas histórias de vida, suas práticas profissionais e todo o processo que envolve a captura, o beneficiamento e a comercialização do caranguejo; vivenciamos a pesca de caranguejo na prática, observando e analisando dois pescadores de caranguejo em diferentes etapas, conforme cada técnica; e desenvolvemos a análise mediante a proposta deste trabalho.

No decorrer da pesquisa identificamos os modos, os saberes e fazeres dos pescadores de caranguejo ao realizar o seu trabalho diariamente. Tais práticas socioculturais mobilizam um vasto conhecimento desenvolvido na região do mangue, o que nos fez compreender os saberes tradicionais dessa atividade. Tendo em vista os aspectos abordados, apresentamos a relação dessa atividade em um olhar etnomatemático.

\section{A Etnomatemática}

O Programa de Pesquisa Etnomatemática surgiu na metade no século $X X$, precisamente a partir da concepção de Ubiratan D'Ambrósio motivado pela busca em compreender o saber/fazer matemático no percurso do desenvolvimento da humanidade inserido no contexto sociocultural de diferentes classes. Nesse propósito, as diferentes formas de pensar, de entender, de valorizar outras culturas foram vistas com mais atenção em relação a essas indagações, pois surge nesse momento um novo cenário de muitas matemáticas, segundo Spengler (apud D’AMBRÓSIO, 2002, p. 16), "não há, porém uma só matemática; há muitas matemáticas". 
O Programa Etnomatemática é interdisciplinar, abrangendo o que constitui o domínio das chamadas ciências da cognição, da epistemologia, da história, da sociologia e da difusão do conhecimento, o que inclui a educação. O que compreende relacionar as "várias matemáticas" predominantes no setor educacional através de um processo contínuo de conhecimento matemático.

Para Mendes (2009, p. 66):

Conhecimento é sinônimo de poder entre as sociedades, pois é a partir dessas concepções que se instituem as diferenças entre Matemática acadêmica e a não acadêmica, visando classificar e distinguir as diferentes categorias de conhecedores e não conhecedores do assunto. Além disso, a detenção de conhecimento se torna um instrumento de dominação e manipulação de situações que podem subordinar as populações de determinados grupos sociais.

O autor aborda que a construção do conhecimento matemático é realizada de forma contínua no que procedem as relações sociais de um determinado grupo a um processo de inserção educacional. Assim, as vivências matemáticas de indivíduos de classes sociais e socioculturais distintas, se ressignificadas no âmbito da Educação Escolar, poderá tornar o ensino de matemática não hierarquizado, rompendo-se com a hegemonia de apenas uma forma de ensino.

Nesse sentido, os modos de ver, pensar, agir, de determinados grupos constituem particularidades no aprendizado do ensino de matemática escolar, ainda tidas como "matemática informal", na verdade resultam de diferentes estruturas e cosmologias de pensamento, ainda "desprezadas", ou preconceituosamente excluídas do "universo escolar", que desconsidera essas formas de saberes e fazeres.

Vivemos em uma sociedade constituída por diferentes manifestações culturais as quais se caracterizam por apresentar conhecimento típico de grupos socioculturais com capacidades de desenvolver técnicas e habilidades de forma natural na arte de explicar, conhecer, entender, compreender de um ambiente específico o que direciona a estudos voltados ao campo da Etnomatemática. Esse conceito compreende o intento da Etnomatemática, como "o estudo comparativo 
de técnicas, modos, artes e estilos da realidade tomada em diferentes meios naturais e culturais" (VERGANI, 2007, p. 25).

[...] Este campo de conhecimento tende a encontrar licitamente o seu lugar interativo simultaneamente no domínio das Ciências da Educação, das Ciências Matemáticas e das Ciências do Homem. Disciplina possível e desejável, capaz de revelar a sua identidade singular, a sua coerência transdisciplinar e a urgência de seu direito à cidadania no nosso sistema sociocultural (VERGANI, 2007, p. 8).

A autora menciona que a Etnomatemática se justifica por apresentar múltiplas relações com o ensino e aprendizagem de matemática o que leva a interação de diversas áreas de conhecimento inseridas no contexto social, cultural e acadêmico proporcionando uma metodologia aceitável no campo educacional, conduzindo a novas formas de relações interculturais.

Diante da construção de conhecimentos que envolvem a Etnomatemática, percebemos a importância dessa linha de pesquisa no âmbito educacional, uma vez que proporciona um vasto leque de conhecimentos matemáticos a serem aplicados como proposta para o ensino de matemática. Dessa maneira, aplicando metodologias que envolvam o ciclo sociocultural do educando a partir de sua realidade, uma melhor assimilação dos conteúdos ministrados é permitida, visto que ocorre a "[...] valorização de conceitos matemáticos informais trazidos pelos próprios alunos a partir de suas experiências fora do contexto escolar" (MENDES, 2009, p.67) .

\section{Pesca de caranguejo: saberes e fazeres}

O processo de pesca do caranguejo requer muitos desafios, além de prática para desenvolver esse trabalho. Dados da pesquisa identificaram que os pescadores de caranguejo de São Caetano de Odivelas não têm um horário específico para realizar seu trabalho na captura, muito menos para a comercialização do produto, essas atividades dependem muito do horário em que a maré deságua do manguezal. 
Existem dois tipos de nomenclatura para designar a pesca do caranguejo: "vai e vem" para quem vai ao manguezal todos os dias e volta para sua casa e "baixada" para quem se locomove e permanece em manguezais distantes do município e, posteriormente, realiza a comercialização ao retornar para casa. Com isso, conclui-se um ciclo semanal de trabalho dessa atividade.

Os pescadores de caranguejo têm como principais meios de transporte: a montaria, embarcação de pequeno porte conduzida a remo; pequenas canoas motorizadas, utilizadas por quem trabalha no vai e vem; embarcações maiores e motorizadas para quem trabalha de baixada.

Para realizar seu trabalho diário, os pescadores de caranguejo que trabalham no "vai e vem" geralmente partem na primeira maré ao amanhecer e remam por algum tempo (depende da distância de sua casa até o manguezal) até o local desejado, amarram suas montarias em árvores, em pequenas pontes improvisadas, posteriormente, entram no manguezal. Em alguns casos, o pescador de caranguejo que trabalha no "vai e vem" não precisa ir de montaria e se direciona ao manguezal a pé ou de bicicleta, isso acontece quando realiza seu trabalho em manguezais de fácil acesso por vias terrestres. Para armazenar o caranguejo, é utilizado saco de fibra sintética. Existe também 0 cofo ${ }^{3}$ para armazenar o caranguejo, sendo esse pouco utilizado, os colaboradores desta pesquisa, por exemplo, só utilizam os sacos.

Já os pescadores de caranguejo que trabalham "de baixada" viajam por algumas horas (depende do local onde irá realizar seu trabalho), sempre em grupos, e, ficam em pequenas barracas ${ }^{4}$ em praias ou até mesmo no próprio manguezal, em um local chamado "teso" ${ }^{5 "}$ por determinado período até o término da sua jornada de trabalho. A realização da pesca de caranguejo é geralmente na baixa mar, ou seja, quando as águas não entram em toda extensão dos

\footnotetext{
${ }^{3}$ É um cesto feito de folhas de palmeiras e tem como utilidade armazenar o caranguejo. Utensílio feito manualmente pelos próprios pescadores de caranguejo.

${ }^{4}$ Pequenas casas que servem como moradia no período em que os pescadores se encontram trabalhando de baixada.

${ }^{5}$ Parte do manguezal que possui solo consistente.
} 
manguezais que, segundo os pescadores de caranguejo, é o momento ideal para fazer a pesca do crustáceo.

Segundo Maciel (2009), obedecendo ao ciclo das marés, o trabalho no manguezal se torna mais acessível para realizar a pesca do caranguejo nas chamadas marés de quarto, ou seja, quando os manguezais não são abrangidos completamente pelas águas, tornando assim um aumento de produção significativo. A autora esclarece ainda que nas marés de sizígia, identificadas pelos pescadores de caranguejo como "maré de lanço", momento em que o manguezal é tomado pelas águas, a captura do caranguejo é limitada, ocasionando um tempo de menor duração na realização do seu trabalho diário. Seguida a "maré de lanço", há a "maré de quadratura", conhecida popularmente pelos pescadores de caranguejo de "águas mortas", sendo o nível da água que entra no mangue menor que a "maré de lanço", o que permite a permanência do pescador por mais tempo no desenvolvimento de seu trabalho no manguezal.

Dados da pesquisa apontam que o ciclo de vida do caranguejo começa no período da reprodução, ocasionando a "andada". O acontecimento da "andada" está ligado ao acasalamento e desova do caranguejo. Tal situação acontece quando os machos e fêmeas, ou seja, caranguejo e condessa saem de suas tocas com a finalidade de acasalar, tornando mais fácil a captura do caranguejo. Esse fenômeno da natureza é conhecido popularmente como "sauatá".

De acordo com os partícipes da pesquisa em São Caetano de Odivelas, há quatro sauatás por ano, iniciando no mês de janeiro e terminando em abril, sendo que do mês de janeiro a março, acontece a reprodução do caranguejo e no mês de abril acontece a desova da condessa, este último é conhecido como sauatá das condessas. Mencionam também que as andadas acontecem de três a cinco dias sempre após a primeira maré de lanço.

Durante o sauatá, acontece o período do defeso, ou seja, época do ano em que é proibida a pesca do caranguejo, pois a legislação da pesca proíbe a captura nesse período. Entretanto, em São Caetano de Odivelas, os pescadores de 
caranguejo não recebem o seguro ${ }^{6}$ defeso disponibilizado pelo Ministério da Pesca.

Depois que termina o período de reprodução, começa outro ciclo para os caranguejos, desta vez, é o momento da engorda e, posteriormente, da ecdise que começa entre os meses de maio e vai até meados de outubro. Nesse período, os caranguejos ficam mais esquivos, mais difíceis de serem capturados, o que torna o valor do produto na comercialização mais elevado.

O caranguejo é um dos recursos do mangue mais explorado pelos pescadores extrativistas de São Caetano de Odivelas, mas para desenvolver qualquer prática que envolva essa atividade é preciso ter conhecimento da cronologia que envolve o ciclo de vida do caranguejo, o qual é dividido em quatro fases: a andada, a desova, a engorda e a ecdise, conhecida como tapado. Para termos melhor concepção acerca das fases que envolvem a pesca de caranguejo. O quadro 01 mostra o desenvolvimento de seu ciclo de vida:

Quadro 01 - Cronologia do ciclo de vida do caranguejo.

\begin{tabular}{|c|c|c|}
\hline CICLO & MÊS & PERÍODo \\
\hline Andada & Janeiro, Fevereiro e Março & Muito Chuvoso \\
\hline Desova & Abril & Muito Chuvoso \\
\hline Engorda & Maio, Junho, Julho e Agosto & Pouco Chuvoso \\
\hline Ecdise & Julho e Agosto & Pouco Chuvoso \\
\hline
\end{tabular}

Fonte: Elaborado pelo autor com dados da pesquisa (2016).

Para capturar o caranguejo é preciso utilizar algumas técnicas. Essas técnicas já vêm sendo utilizadas há muitos anos, atravessando gerações, possibilitando o manuseio dessa atividade. Nesse contexto, compreendemos que

\footnotetext{
${ }^{6}$ É um benefício pago ao pescador que fica proibido de exercer a atividade pesqueira durante o período de defeso de alguma espécie. Disponível em: $<$ https://www.google.com.br/webhp?sourceid=chrome-instant\&ion=1\&espv=2\&ie=UTF-8\#q $>$. Acesso: 12 jun. 2016.
} 
as técnicas não mudam, mas tornam-se sempre evolutivas no que se refere ao uso das mesmas.

\section{Técnicas de Captura}

A técnica a ser utilizada pelos pescadores de caranguejo no ato de seu trabalho é determinada pelo período climático em que o município de encontra, ou seja, muito chuvoso ou pouco chuvoso. No contexto da pesquisa realizada, os pescadores de caranguejo apontaram quatro técnicas para realizar a pesca do caranguejo, apresentadas a seguir.

\subsection{Braçal}

Essa técnica permite ao pescador de caranguejo introduzir o braço na toca do caranguejo e com certa habilidade pegá-lo com as mãos, percebendo, assim, o tamanho e o sexo do crustáceo, e com a sua experiência nessa atividade, o pescador analisa se tira ou não o caranguejo do local onde se encontra. Hoje, essa técnica é pouco usada pelos pescadores de caranguejo do município, sendo utilizada mais no período muito chuvoso. A Figura 01 mostra o pescador de caranguejo utilizando a técnica braçal.

Figura 01 - Pescador de caranguejo utilizando a técnica braçal.

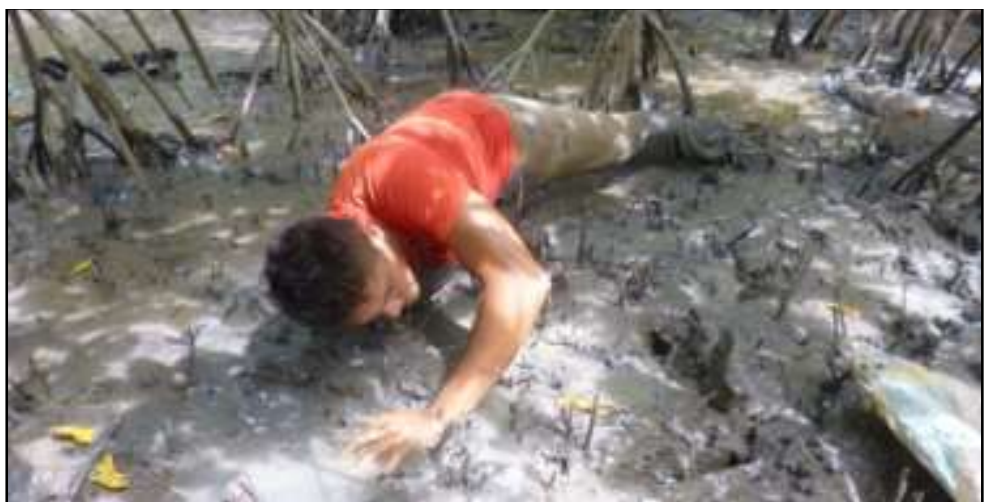

Fonte: Arquivo pessoal (2014). 
Dentre os colaboradores desta pesquisa, dois afirmam utilizar a técnica braçal para capturar o caranguejo e, analisando suas falas, percebemos que essa técnica é a que menos corrompe o ecossistema em relação às outras técnicas.

\subsection{Tapagem}

Essa técnica consiste em tapar a toca do caranguejo que fica assim de uma a duas horas para, posteriormente, ser realizada a captura do crustáceo, entretanto, somente os caranguejos aptos à comercialização são capturados. Essa técnica é uma das mais utilizadas pelos pescadores de caranguejo de São Caetano de Odivelas. Essa técnica tem esse nome pelo fato do pescador de caranguejo jogar lama na entrada das tocas com o objetivo de deixar o caranguejo sem ar, fazendo com que o crustáceo venha até a superfície, o que propicia a sua captura. A Figura 02 mostra a utilização da técnica da tapagem.

Figura 02 - Toca do caranguejo tapado.

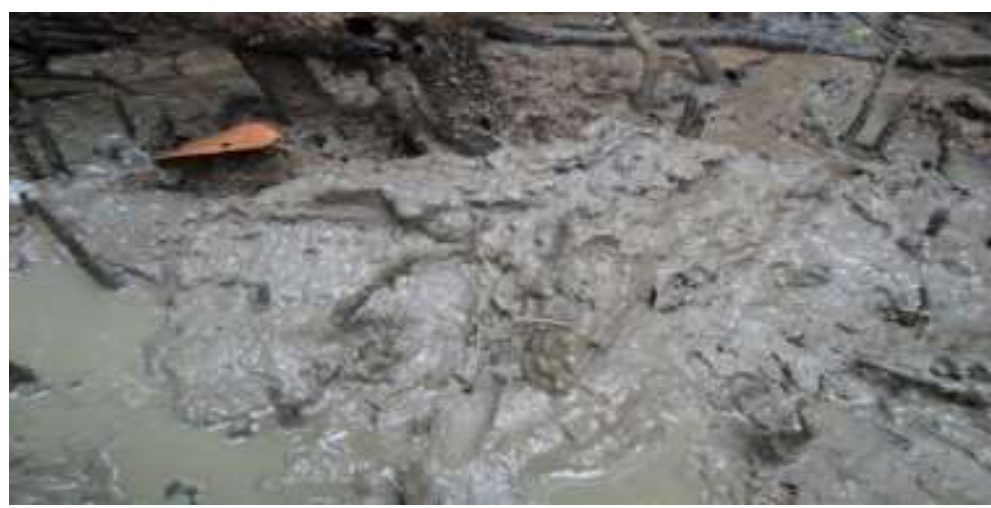

Fonte: Arquivo pessoal (2014).

Essa técnica é utilizada pelos três pescadores de caranguejo colaboradores desta pesquisa. De acordo com os mesmos, ao adentrar no manguezal o pescador de caranguejo localiza seu espaço e depois vai realizando a tapagem. Os trabalhadores revelam que para não esquecer o local, o pescador marca a raiz do mangueiro ${ }^{7}$ com uma bola de barro. Em seguida, espera de uma hora e meia a duas horas para voltar ao manguezal e verificar as tocas tapadas

\footnotetext{
${ }^{7}$ Árvore com raiz grande típica do manguezal.
} 
para realizar a captura do caranguejo. Essa técnica pode ser utilizada tanto nos períodos muito chuvoso e quanto no período pouco chuvoso.

\subsection{Laço}

A técnica do laço é feita através de uma pequena vara de aproximadamente trinta centímetros de comprimento e de um fio de náilon com o mesmo tamanho da vara. O pescador amarra o fio na ponta da vara e dá um nó corrente na sua extremidade, fazendo uma circunferência com o mesmo tamanho da entrada da toca do caranguejo, permitindo assim, armar o laço. Ao utilizar essa técnica no manguezal, o pescador introduz a vara nas proximidades da toca do caranguejo, arma o laço em formato de triângulo, formando uma espécie de armadilha, com isso, o caranguejo ao sair para a superfície fica preso no entrelaçado do náilon, impossibilitando-o de sair. A técnica do laço é utilizada pelos três participantes desta pesquisa. A figura 03 apresenta o laço armado no manguezal.

Figura 03 - Laço armado para fazer a captura do caranguejo.

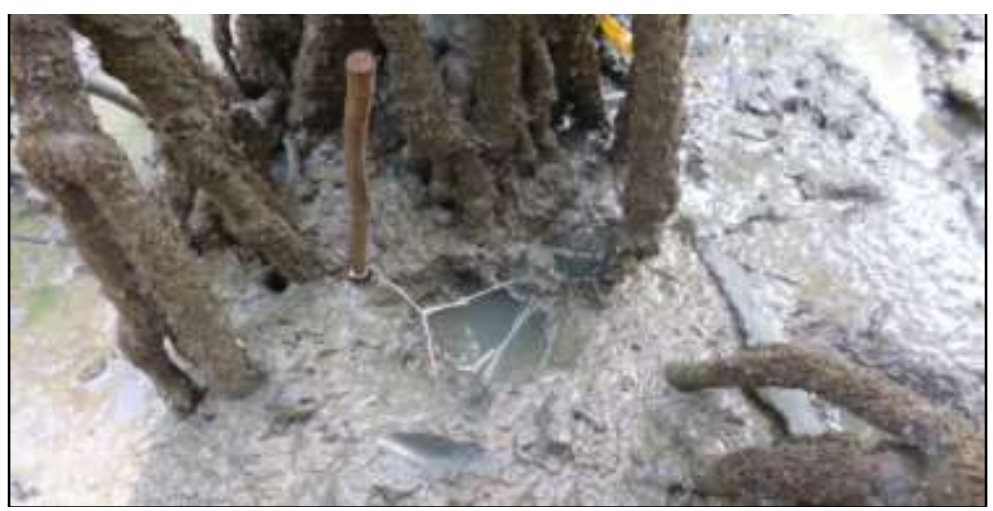

Fonte: Arquivo pessoal (2014).

Segundo os colaboradores desta pesquisa, o laço é a técnica que mais se utiliza em São Caetano de Odivelas. Após colocar o laço, o pescador de caranguejo identifica o local com uma bola de barro nas raízes dos mangueiros para não esquecê-los, em seguida os deixam armados por 24 horas e, no dia seguinte, fazem a captura do caranguejo. 


\subsection{Gancho}

Nessa técnica é utilizada uma haste grande. Ao utilizá-la o pescador introduz a haste até a localização do caranguejo para em seguida puxar até à superfície. Essa técnica é pouco utilizada pelos pescadores de São Caetano. Nenhum dos colaboradores da pesquisa a utiliza. A Figura 04 mostra a utilização da técnica do gancho.

Figura 04 - Caranguejeiro utilizando o gancho para capturar caranguejo.

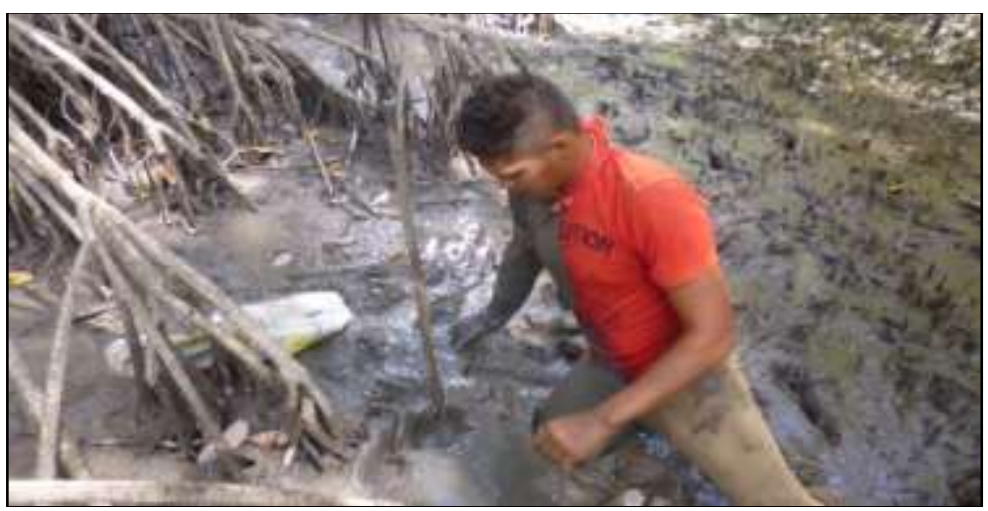

Fonte: Fotografia do autor (2014)

Dentre as técnicas apresentadas, as mais utilizadas pelos pescadores de caranguejo de São Caetano de Odivelas são o laço, a tapagem e a braçal, a técnica do gancho quase não é praticada, porém, segundo os colaboradores da pesquisa, a técnica do laço é a que mais dá resultado, permitindo um índice elevado de caranguejos capturados comparando com as demais técnicas.

Souto (2009) fala que a utilização da técnica de captura do caranguejo está relacionada com os fenômenos ambientais inseridos na realização dessa atividade como os ciclos das marés, o ciclo de vida do caranguejo, os ciclos lunares que influenciam todo o processo de beneficiamento e na conservação desse recurso natural.

Nesse contexto, outro fator que intervém no ciclo de vida do caranguejo e na utilização das técnicas de captura é o calendário lunar. Segundo os pescadores de caranguejo, todo pescador precisa ter conhecimento acerca das fases da lua para realizar com êxito o seu ciclo de trabalho. Na pesquisa, foi identificado que os pescadores de caranguejo consideram as fases da lua como 
uma espécie de guia, pois para a realização de suas atividades é necessário saber o estado em que a maré se encontra. Segundo os mesmos, quando é lua cheia ou lua nova a maré está de lanço e quando é lua crescente ou lua minguante a maré esta de morta. Para Almeida (2012), as fases da lua são contadas três dias antes e três dias depois de cada lua o que determina um ciclo de observações pelos pescadores de caranguejo.

De acordo com Almeida (2012), no período da lua minguante a maré está de morta, assim depois de três dias após o dia da lua a maré vai entrando cada vez mais até inundar todo o manguezal, chega então, o período da lua nova, sendo que nessa fase da lua o manguezal fica submerso devido à maré está de lanço. Segundo a autora, após o dia da lua nova a maré vai diminuindo a cada dia até que "quebra", ou seja, chega ao nível normal, momento em que termina o período do lanço. Em seguida, após três dias desse período surge a lua crescente, a partir desse novo ciclo, a maré novamente vai adentrando ao manguezal pouco a pouco até que no terceiro dia surge a lua cheia, momento em que o manguezal fica mais uma vez submerso. A autora afirma também que, após o dia da lua cheia, a maré vai saindo do manguezal até que no terceiro dia surge a lua minguante, concluindo assim, o ciclo lunar.

Desse modo, ressalto que esses conhecimentos facilitam o exercício das atividades dos pescadores de caranguejo o que possibilita utilizá-los de maneira coerente a cada ciclo apresentado. Esses saberes são reflexos de experiências e de conhecimentos adquiridos ao longo do seu processo de transformação, pois "o conhecimento é o gerador do saber, decisivo para a ação e, por conseguinte, é no comportamento, na prática, no fazer, que se avalia, redefine e reconstrói o conhecimento" (D'AMBROSIO, 2002, p. 53).

\footnotetext{
${ }^{8} \mathrm{Na}$ linguagem dos pescadores de caranguejo é o momento em que termina o lanço, ou seja, a maré não fica submersa ao manguezal.
} 


\section{Um olhar etnomatemático sobre os saberes e fazeres de pescadores de caranguejo}

Neste estudo, fizemos uma análise Etnomatemática acerca dos saberes e fazeres das atividades cotidianas de pescadores de caranguejo de São Caetano de Odivelas/PA. Nesse propósito, por meio das informações relacionadas aos conhecimentos tradicionais dos atores partícipes deste trabalho, os dados da pesquisa vieram ao encontro da proposta da referida análise.

Moreira (2012) argumenta que os saberes tradicionais são reflexos do envolvimento entre sociedade e natureza e a utilização desses saberes está vinculada ao desenvolvimento social e cultural constituído pela sociedade.

Desse modo, mediante todo processo que envolve a atividade tradicional dos pescadores de caranguejo, cheia de saberes culturais em virtude da vida cotidiana desses indivíduos, surge o saber/fazer matemático presente nessa atividade cujo interesse é a busca de explicações nas diferentes maneiras de abarcar a vida social e cultural inserida na pesca de caranguejo.

Analisando o comportamento dos pescadores de caranguejo colaboradores desta pesquisa - identificamos que a jornada de trabalho diária apresentada pelos mesmos não tem um horário específico para ser realizada, uma vez que é necessário saber qual o horário que a maré deságua do manguezal, pois a mesma tem movimentos diferentes a cada dia, como menciona o pescador de caranguejo Antônio:

"O pescadores de caranguejo não tem um horário certo pra ir pro mangal, depende muito da hora que a maré sai do mangue. Às vezes, eu saio de casa às cinco horas da manhã, às vezes eu saio às cinco e meia e tem dias que eu saio mais tarde ainda, depende muito como está a maré, porque eu ainda tenho que remar até chegar no mangal e dependendo de onde seja, eu saio cedo ou não. Como eu trabalho há muito tempo pegando caranguejo, eu já sei o horário que eu tenho que sair de casa pra chegar na hora certa de entrar no mangal".

O pescador de caranguejo ressalta a influência da maré para a realização da captura do caranguejo. Segundo o mesmo, o horário de saída de sua casa 
para o manguezal acontece de acordo com o local onde pretende realizar a captura do crustáceo e de como a maré se encontra, ou seja, o ciclo da maré determina o horário em que o pescador de caranguejo deve ir ao local de captura do crustáceo. Diante do exposto, o referido caranguejeiro estabelece uma relação espaço-tempo de acordo com o horário da maré, cuja temporalidade é determinante no processo de organização da tarefa de captura, desde a hora de acordar, sair de casa e chegar ao local de trabalho. Assim, de acordo com a maré e quanto mais longe for o local de captura no manguezal, a organização e o planejamento se diferenciam. Nesse contexto, ocorre toda uma logística referente ao tempo de saída da casa, tempo de chegada ao manguezal e tempo de realização da captura do caranguejo, todas essas etapas devem ser cumpridas de acordo com o horário e tempo em que a maré entra e deságua no manguezal.

Esse cenário é de conhecimento dos pescadores de caranguejo, pela habitualidade com o ciclo das marés, assim como as que apresentam melhores condições de trabalho ao extrativista. Nesse sentido, existem três tipos de marés:

$1^{\text {a) }}$ Maré de quarto a qual não submerge todo o espaço do manguezal;

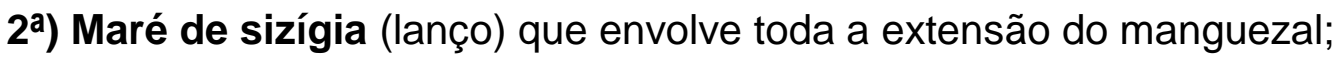

$3^{a}$ ) Maré de quadratura (morta) que não abrange todo o espaço do manguezal.

Com essas informações, o tempo e espaço tornam-se os aliados dos caranguejeiros. Relacionando os três tipos de marés, é perceptível que os mesmos obtêm um melhor resultado ao trabalhar nas marés de quarto e quadratura, cujo rendimento será mais favorável em virtude da maré não submergir todo o espaço do manguezal nos referidos períodos, o que torna o tempo disponível para captura maior o que certamente influenciará nos resultados. Já no período de sizígia isso não acontece, pois ao tomar todo o espaço do manguezal, a maré custa a sair o que faz com que o pescador de caranguejo tenha um tempo mais curto para realizar o seu trabalho o que certamente implicará em resultados inferiores. Assim, identifico no ciclo das marés a importância em estudar os fenômenos da natureza, neste caso, tendo 
como aliado o tempo e o espaço geográfico presentes no dia a dia dos pescadores de caranguejo.

A pesca do caranguejo é realizada de acordo com o ciclo de vida do caranguejo e o período climático amazônico, para isso é preciso ter conhecimento de todo o processo que envolve essa atividade. Pela pesquisa, ressaltamos que esse ciclo é conceituado da seguinte forma:

1) A andada: realizada no período de janeiro a março (muito chuvoso);

20) A desova: no mês de abril (muito chuvoso);

$3^{\circ}$ ) A engorda: no período de maio a agosto (pouco chuvoso);

4\%) A ecdise: no período de julho a agosto (pouco chuvoso).

De acordo com a pesquisa, o pescador de caranguejo é ciente da cronologia do ciclo de vida do caranguejo. Nesse sentido compreendemos que:

a) $\mathrm{Na}$ andada e na desova, períodos em que acontece a reprodução do caranguejo, que vai de janeira a abril, o pescador tem uma demanda de trabalho menor quando comparada a outros meses do ano, exceto no período da ecdise. Além disso, nesses ciclos ocorre o período do defeso no qual o pescador de caranguejo fica impossibilitado de realizar a comercialização do crustáceo por um tempo que varia de três a cinco dias, porém o valor do caranguejo fica em alta com um aumento em torno de $30 \%$, entretanto é o período em que há uma baixa produtividade, uma vez que ocorre o inverno amazônico no qual a demanda de chuvas é sempre elevada o que afeta negativamente o trabalho dos pescadores.

b) A engorda e a ecdise que, segundo os partícipes da pesquisa, são os períodos em que o caranguejo está gordo e mais saboroso, também é o melhor momento para comercializar o crustáceo, uma vez que não está mais na época do defeso. Entretanto nos meses de julho a agosto acontece o período da ecdise, o que torna a captura mais difícil de ser realizada, contudo o valor da venda fica igualado com os mesmos períodos do acasalamento e da desova. De acordo com Maciel (2009), no período da engorda o caranguejo muda seu comportamento, ficando mais difícil de capturá-lo, no entanto por apresentar um sabor diferenciado torna-se mais valorizado economicamente. Entre os meses de setembro a 
dezembro, o caranguejo fica magro, mesmo assim é o período em que a pesca tem um índice elevado na captura do crustáceo, o que torna o valor mais baixo ao ser comercializado.

Com essas informações, ressaltamos que o ciclo de vida do caranguejo influencia diretamente no cotidiano dos extrativistas, o que foi compreendido por Vasconcelos (2008), em Ilhéus/BA, ao observar que tais conhecimentos são obtidos pelos pescadores de caranguejo ao vivenciar na prática 0 desenvolvimento dessa atividade. Com base nesses conhecimentos, comparando a pesca realizada na ocasião da andada e na desova com a da engorda e da ecdise, compreendemos que os meses de maio e junho, período da engorda, geram melhores resultados na comercialização do crustáceo, pois nesses meses a captura do caranguejo é feita constantemente, o que resulta em uma quantidade maior de caranguejos capturados, além de apresentar valores significativos na comercialização.

Algo inserido no ciclo das marés e que influencia diretamente no ciclo de vida do caranguejo é o calendário lunar. Para D’Ambrósio (2002), os calendários sintetizam o conhecimento e o comportamento em função da evolução de uma atividade cultural. Nesse aspecto, o pescador identifica, através das fases da lua, contagem e registro de tempo o que influencia diretamente na escolha do tipo de técnica de captura que será utilizada na pesca do caranguejo. Mediante ao processo das técnicas de capturas e com base nas informações do ciclo lunar, faço as seguintes análises:

a) A técnica do laço só pode ser utilizada no período da lua crescente e minguante, pois é preciso deixar o laço armado no manguezal por aproximadamente 24 horas, sendo colocado em um dia e retirado no outro e para tal situação é preciso que o manguezal esteja sólido, propício a ser utilizado. No período da lua nova e lua cheia o manguezal fica totalmente cheio pela maré, impossibilitando a utilização dessa técnica.

b) Ao relacionar a técnica da tapagem com o calendário lunar, compreendemos que essa técnica é mais apropriada para ser realizada no período da lua nova e 
da lua cheia, uma vez que o manguezal fica submerso em decorrência da entrada da maré, assim a lama fica mole, facilitando o uso dessa técnica. Segundo os participantes da pesquisa, no período da lua crescente e lua minguante, o manguezal fica mais sólido o que dificulta a técnica da tapagem, bem como a braçal, pois demanda um esforço maior do pescador devido às dificuldades encontradas para a realização da mesma.

c) As técnicas, braçal e gancho, pela forma como são aplicadas, podem ser utilizadas em todas as fases da lua, pois a realização das mesmas é feita diretamente na toca do caranguejo. Diferente das demais técnicas que precisam do momento certo para serem praticadas.

Analisando os períodos (muito chuvoso e pouco chuvoso) de comercialização retratado pelos colaboradores da pesquisa, compreendemos que a produtividade do caranguejo no período pouco chuvoso é maior comparada com a do período muito chuvoso, porém, nesse período, a comercialização é mais vantajosa em consequência do valor da venda do produto ser mais elevado. No entanto, no período de janeiro a abril, o tempo de trabalho é menor comparado com os demais meses em consequência de ser o período que limita o período de trabalho a ser realizado. Desse modo, vale dizer que o tempo é o principal responsável em manter o equilíbrio da pesca do caranguejo, ou seja, o tempo para chegar ao manguezal, o tempo de permanência no local de trabalho, o tempo de vida do caranguejo e o melhor tempo para comercializar.

\section{Para finalizar...}

Com o reconhecimento da importância da valorização dos conhecimentos desenvolvidos por diversos grupos socioculturais e sua importância para a Educação Escolar, possibilitam interações não apenas com o conhecimento matemático, mas com outros saberes escolares que poderiam ser trabalhados de forma articulada a partir de tematizações, de acordo com a realidade local, como no caso da temática apresentada neste texto. 
No decorrer do estudo realizado, pudemos verificar e identificar os processos de organização e difusão de conhecimentos dos pescadores de caranguejo. Além do conhecimento do desenvolvimento social, profissional e cultural em que os pescadores estão inseridos, o estudo resultou em uma experiência gratificante e de grande aprendizado e que nos fez perceber o universo de saberes que regem ao seu comportamento diário e a sua própria vida.

Dentre esses saberes mencionamos o pescador de caranguejo como um verdadeiro conhecedor das ações relacionadas à sua atividade, pois, por meio do seu conhecimento tradicional, ele sabe lidar com os efeitos do tempo, do espaço, das marés, dos manguezais, das relações comerciais que envolvem a pesca de caranguejo, bem como outras situações dela decorrentes. São verdadeiros conhecedores do envolvimento entre homem e natureza, o que lhes propicia fonte de subsistência, e permite compreender que "a interação do indivíduo com a realidade, da qual ela é parte integrante e agente de transformação, é o grande desafio das ciências da cognição, particularmente da inteligência artificial" (D’AMBRÓSIO, 2002, p.53).

Ressaltamos que conhecer a realidade dos pescadores de caranguejo foi fundamental para a compreensão de seus saberes e fazeres, para ampliar o entendimento de como as práticas sociais de grupos podem ser extremamente ricas na mediação da apreensão de conceitos e operações não só matemáticas, mas do pretenso conhecimento produzido pela escola, a partir do seu contexto cultural.

\section{Referências}

ALMEIDA, Neila de Jesus Ribeiro. Saberes e práticas tradicionais: população pesqueira extrativista da vila Sorriso São Caetano de Odivelas/PA. 2012. $110 f$. Dissertação (Mestrado em Gestão dos Recursos Naturais e Desenvolvimento Local na Amazônia) - Universidade Federal do Pará, Belém, 2012. 
BARTON, Bill. Dando sentido a etnomatemática: etnomatemática fazendo sentido. In: DOMITE, M. C. S.\& FERREIRA, R. \& RIBEIRO, J.P.M. (orgs.). Etnomatemática: papel, valor e significado. São Paulo: Zouk, 2004.

D’AMBROSIO, Ubiratan. Etnomatemática - elo entre as tradições e a modernidade. 2ed. Belo Horizonte. Autentica, 2002.

KNIJNIK, Gelsa; WANDERER, Fernanda; GIONGO, leda Maria; DUARTE, Claudia Glavam. Etnomatemática em movimento.-2. ed. - Belo Horizonte: Autêntica Editora, 2013. (Coleção Tendências em Educação Matemática, 25).

MACIEL, Ivana Lúcia Sarmento. O mangue como unidade geográfica de análise: o espaço de vivência e produção comunitária nos manguezais da comunidade Jutaí no município de São Caetano de Odivelas - PA. 2009. 121f. Dissertação (Mestrado em Geografia) - Universidade Federal do Pará, Belém, 2009

MENDES, Iran Abreu. Matemática e investigação em sala de aula: tecendo redes cognitivas na aprendizagem. Ed. rev. e aum. São Paulo: Editora Livraria da Física, 2009.

MOREIRA, Sílvia. O saber e fazer da comunidade tradicional caiçara da praia do Bonete na Ilhabela. 2009. 147f. Dissertação (Mestrado em História da Ciência) Pontifícia Universidade Católica de São Paulo, PUC - SP. São Paulo - SP, 2012.

SOUTO, Francisco José Bezerra. A ciência que veio da lama: uma abordagem etnoecológica das relações ser humano/manguezal na comunidade pesqueira de Acupe, Santo Amaro - BA. 2004. 319p. Tese (Doutorado em Ecologia e Recursos Naturais) Universidade Federal de São Carlos, São Carlos, SP, 2004.

VASCONCELOS, Jussiara Lopes de Almeida. Biologia do caranguejo-uçá e perfis sócio-econômico e etnobiológico dos coletores em duas áreas de manguezais em Ilhéus-BA. 2008. 103 f. Dissertação (Mestrado em Desenvolvimento Regional e Meio Ambiente) - Universidade Estadual de Santa Cruz, Ilhéus - BA, 2008.

VERGANI, Tereza. Educação etnomatemática: o que é? Natal-RN: Flecha do tempo, 2007. 